\section{UK retinopathy of prematurity treatment survey}

Southampton Eye Unit, Southampton, UK

Correspondence:

F Cuthbertson,

Department of

Ophthalmology,

Milton Keynes General

Hospital,

Standing Way,

Eaglestone,

Milton Keynes,

Buckinghamshire

MK6 5LD, UK

Tel: + 441908243 416;

Fax: +44 1908243714 .

E-mail: fcuthbertson@

doctors.org.uk

Received: 22 February 2005 Accepted in revised form: 30 June 2005

Published online: 27 January 2006

\begin{abstract}
Background Since the CRYO-ROP study showed the benefit of treating babies with ROP, a number of different treatment modalities have become available. Solid-state lasers have been extensively used in the treatment of ROP since their introduction some 10 years ago. Diode, argon and frequencydoubled YAG (FD-YAG) lasers have all been used to perform photocoagulation in ROP. We aimed to assess current treatment practices of ROP treatment in the UK.

Methods A questionnaire survey was performed in June 2004 and sent to all consultants known to be involved in the treatment or screening of ROP patients. We asked about the number of patients treated in the last year, the treatment method, and whether there had been any serious complications.
\end{abstract}

Results In all, 53 questionnaires were sent out, of which 42 were returned. Also, 30 respondents treated ROP. Of these 19 used transpupillary diode, 11 argon, and three FDYAG. Cryotherapy and transscleral diode laser were used by two centres in particular cases. In all, 20 patients were treated with FD-YAG, 21 with argon laser, and 188 with diode laser. The number of burns per eye varied from 800 to 2500. Reported complications included hyphaema, retinal haemorrhage, and acute cataract formation; however, there was no significant difference in complications between different types of laser used.

Discussion This survey of laser use in the treatment of ROP has shown that diode laser is now the most common mode of treatment in the UK. The incidence of complications was similar for centres using argon, diode, or FD-YAG laser.

Eye (2007) 21, 156-157. doi:10.1038/sj.eye.6702230; published online 27 January 2006

Keywords: retinopathy of prematurity; treatment; laser
F Cuthbertson and R Newsom

\section{Introduction}

Since effective treatment of retinopathy of prematurity (ROP) was shown by the CRYOROP study, ${ }^{1}$ increased availability of portable solid-state lasers has enabled indirect laser photocoagulation to be used in neonatal units. Results of initial trials involving diode lasers are encouraging with anatomical outcomes at least as good as cryotherapy. ${ }^{2}$ Evidence for use of other lasers is less clear.

We aimed to assess current UK practice looking at the spectrum of treatments and reported side effects.

\section{Methods}

A questionnaire was sent to UK ophthalmologists with an interest in ROP, asking about treatment modality, numbers treated, and complications.

\section{Results}

In all, 42/53 questionnaires (79\%) were returned, 12 did not treat ROP. The frequency of ROP treatment varied, with most treating small numbers (Figure 1). Of the 30 completed questionnaires, 19 (63\%) used trans-pupillary diode, $11(37 \%)$ argon and three (10\%) FD-YAG. One used cryotherapy and one transscleral diode (Figure 2).

Indirect diode laser was used significantly more than any other modality $(P<0.04)$. Also, $188 / 229$ babies were treated with diode laser,

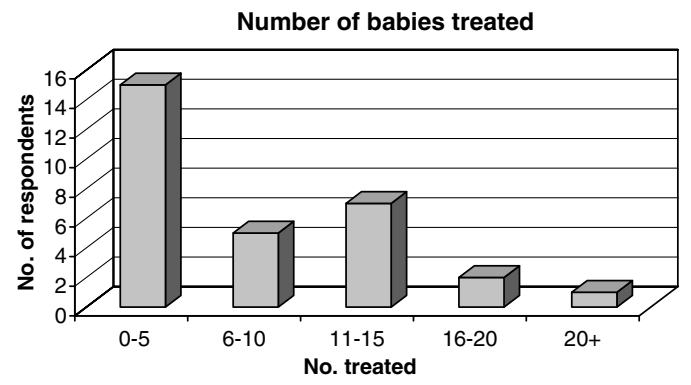

Figure 1 Reported number of patients treated by UK ophthalmologists. 


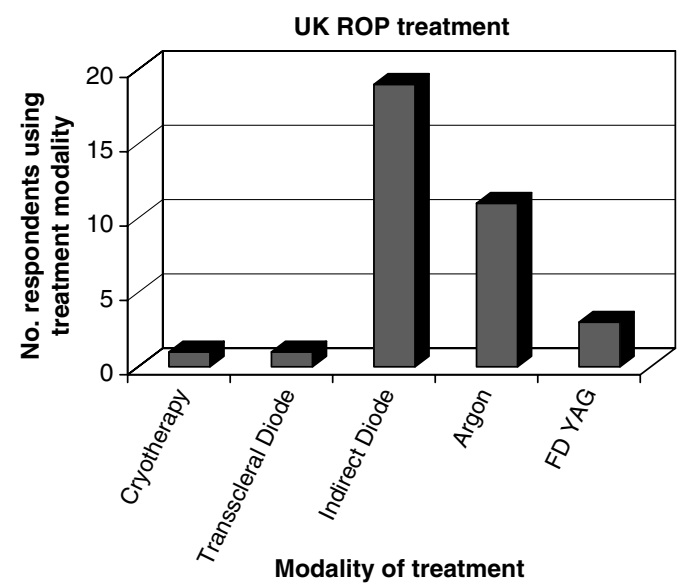

Figure 2 Usage of treatment modalities for the treatment of ROP in the UK.

with four hyphaemas, one eye with posterior synechiae, and three re-treatments; $21 / 229$ babies were treated with argon laser, with one haemorrhage and no re-treatments; and 20/229 patients were treated with FD-YAG laser, with two cataracts and two re-treatments.

\section{Discussion}

A variety of lasers and delivery methods have been used in ROP. ${ }^{3}$ In the treatment of threshold ROP most studies looked at diode laser, and showed outcomes at least as good as cryotherapy. ${ }^{4-9}$ Some trials compared the two modalities, ${ }^{2,10-15}$ showing structural outcomes for laser at least as good as for cryotherapy. For trials collecting visual data, visual acuity also seems as good or better in the laser groups compared to cryotherapy groups. ${ }^{16}$

Both treatments have complications..$^{3,15,17-19}$ Our small sample may have underreported both complications and the need for re-treatment, as it relied on each reporting ophthalmologist's memory. Laser offers a cheaper treatment alternative to cryotherapy. ${ }^{3}$

UK practice has moved away from cryotherapy towards laser treatment. Recent studies indicated a likely benefit of laser over cryotherapy. There is little evidence as to whether one modality of laser treatment is superior to another. It may be useful to collect nationwide data regarding treatment modality, outcome and complications to build up a better picture of any differences between lasers.

\section{References}

1 Cryotherapy for Retinopathy of Prematurity Cooperative Group. Multicenter trial of cryotherapy for retinopathy of prematurity: preliminary results. Arch Ophthalmol 1988; 106: 471-479.

2 McGregor ML, Wherley AJ, Fellows RR, Bremer DL, Rogers GL, Letson AD. A comparison of cryotherapy versus diode laser retinopexy in 100 consecutive infants treated for threshold retinopathy of prematurity. J AAPOS 1998; 2(6): 360-364.

3 Good WV, Hardy RJ, Dobson V, Palmer EA, Phelps DL, Quintos M. Revised indications for the treatment of retinopathy of prematurity. Arch Ophthalmol 2003; 121(12): 1684-1697.

4 Ho JD, Yang CM, Ho TC, Chen MS, Yau K-YT, Kua KE. Diode laser photocoagulation for retinopathy of prematurity. Six years experience. Tzu Chi Med J 1997; 9(4): 265-272.

5 Seiberth V, Linderkamp O, Verdarli I, Knorz MC, Liesenhoff $\mathrm{HH}$. Dioden laser Koagulation der retinopathia praematurorum stadium 3+. Ophthalmologie 1996; 93: 182-189.

6 McNamara JA, Tasman W, Vander JF, Brown GC. Diode laser photocoagulation for retinopathy of prematurity: preliminary results. Arch Ophthalmol 1992; 110: 1714-1716.

7 Fallaha N, Lynn MJ, Aaberg Jr TM, Lambert SR. Clinical outcome of confluent laser photocoagulation for retinopathy of prematurity. J AAPOS 2002; 6(2): 81-85.

8 Foroozan R, Connoly BP, Tasman WS. Outcomes after laser therapy for threshold retinopathy of prematurity. Ophthalmology 2001; 108(9): 1644-1646.

9 Connolly BP, McNamara JA, Reguio CD, Tasman W, Sharma S. Visual outcomes after laser photocoagulation for threshold ROP. Ophthalmology 1999; 106(9): 1734-1737.

10 Paysse EA, Lindsey JL, Coats DK, Contant CF, Steinkuller PG. Therapeutic outcomes of cryotherapy versus transpupillary diode laser photocoagulation for threshold retinopathy of prematurity. J AAPOS 1999; 3(4): 234-240.

11 Hunter DG, Repka MX. Diode laser photocoagulation for retinopathy of prematurity: a randomized study. Ophthalmology 1993; 100: 238-244.

12 White J, Repka MX. Randomized comparison of diode laser photocoagulation versus cryotherapy for threshold retinopathy of prematurity: 3 year outcome. J Pediatr Ophthalmol Strabismus 1997; 34: 83-87.

13 Connolly BP, McNamara JA, Sharma S, Regillo CD, Tasman W. A comparison of laser photocoagulation with transscleral cryotherapy in the treatment of threshold retinopathy of prematurity. Ophthalmology 1998; 105: 1628-1631.

14 The Laser ROP Study Group. Laser therapy for retinopathy of prematurity (letter). Arch Ophthalmol 1994; 112: 154-156.

15 Shalev B, Farr AC, Repka MX. Randomized comparison of diode laser photocoagulation versus cryotherapy for threshold retinopathy of prematurity: 7 year outcome. Am J Ophthalmol 2001; 132(1): 76-80.

16 Early Treatment for Retinopathy of Prematurity Cooperative Group. Revised indications for the treatment of retinopathy of prematurity: results of the early treatment for retinopathy of prematurity randomized trial. Arch Ophthalmol 2003; 121: 1684-1694.

17 Paysse EA, Miller A, Brady McCreery KM, Coats DK. Acquired cataracts after diode laser photocoagulation for threshold retinopathy of prematurity. Ophthalmology 2002; 109(9): 1662-1665.

18 Lee GA, Lee LR, Gole GA. Angle closure glaucoma after laser treatment for retinopathy of prematurity. J AAPOS 1998; 2(6): 383-384.

19 Mulvihill A, Lanigan B, O'Keefe M. Bilateral serous retinal detachments following diode laser treatment for retinopathy of prematurity. Arch Ophthalmol 2003; 121(1): 129-130. 